\title{
Prediction of Oil Critical Rate in Vertical Wells using Meyer-Gardner Correlations
}

\section{OLORO, J}

\author{
Department of Petroleum and Gas Engineering, Faculty of Engineering, Delta State University, Abraka, Delta State, Nigeria \\ Email: joloroeng@yahoo.com
}

\begin{abstract}
This paper investigates the prediction of oil critical rate in vertical wells using Meyer-Gardner correlations by developing a computer program to determine the oil critical rate for a vertical well in a reservoir system. The results obtained from manual computation and prediction using the program is the same. This shows that the program developed is reliable. The results also shown that perforated interval, pay-zone thickness and fluid properties affect critical oil rate.
\end{abstract}

DOI: https://dx.doi.org/10.4314/jasem.v22i4.26

Copyright: Copyright (C) 2018 Oloro. This is an open access article distributed under the Creative Commons Attribution License (CCL), which permits unrestricted use, distribution, and reproduction in any medium, provided the original work is properly cited.

Dates: Received: 17 March; Revised: 14 April: 2018; Accepted: 27 April 2018

Keywords: Breakthrough, Time, Reservoir, Coning

Coning is a mechanism that describes the movement of water from lower to higher and/or movement of gas from higher to lower into the perforations of a producing oil well which can affect the well productivity (Wheatley, 1985).In oil and gas production, adequate planning are put in place to prevent any production-problems, such as coning problem (Anietie et al., 2017).Coning can exhibit detrimental impacts on operations, recovery, and economics in oil production. Some of the specific drawbacks of coning in oil producing wells as given by (Ahmed, 2000) comprises: depletion mechanism efficiency reduction, decrease in oil flow rate, increased cost of surface handling installations for increased quantity of produced water accompanied with its disposal cost as produced water is mostly corrosive. Coning happens around the well when water moves up from the free water level and /or gas moves down in a vertical direction from the gas cap (Armenta, 2003). Due to capillary pressure effect, a transition zone may occur at the interface boundary as sharp fluid interfaces is only an engineering idealization (Ike, 2011).It is usual thing in petroleum reservoir coning modeling to neglect capillary forces (Chaperon, 1986,Papatzacos,1991). As oil production occurs, fluid equilibration state within the reservoir is perturbed and thus a differential pressure is introduced around the producing well that is often known to be viscous drag (Yang and Wattenbarger, 1991). At unsteady-state condition, progression of the cone towards the well with time - depicting an unstable (Giger, 1989). The time period between production commencements from original condition to when the unwanted fluid cones into the well is known as the breakthrough time (Ayeni, 2008).Coning is as a result of declined in pressure around the perforation zone and the presence of a strong water aquifer or gas cap (Kwame, 2014).Coning is a petroleum engineering problem since oil found below a gas zone, or above water zone (Ike, 2013).The aim and objectives of this paper is to predict oil critical rate in vertical wells using Meyer Grader correlations and determination of effect of perforated Interval, pay-zone thickness and fluid properties on critical oil rate.

\section{MATERIALS AND METHODS}

Presentation of Meyer and Garder model (1954) and collection of reservoir data and properties of fluid for vertical wells was carried out. There after manual prediction of the critical rate of oil of the various coning systems was done using reservoir data and properties of fluid for the three systems concern. Visual basic programming language was developed to find the critical oil rate for the three systems of concern.

Presentation of Meyer and Gardner Model: The mathematical treatise as given by Meyer - Gardner was founded on the theory of flow in porous media as presented by Hubbert (Hubbert, 1956). Stable gas cone is necessary for Meyer and Gardner correlation to be used to determine critical oil rate with the following information: Oil and Gas density difference $\left(\rho_{\mathrm{o}}-\rho_{\mathrm{g}}\right)$; Depth $\mathrm{D}_{\mathrm{t}}$ from (GOC) to the perforations top; the height of oil column $h$.

Perforated interval $h_{p}$, in a gas-oil system, is defined 
as the difference between the height of oil column and the depth from the original gas-oil contact to the top of the perforations:

That is, $h_{p}=h-D_{t}$

The following expression was presented by Meyer and Garder for computing the oil critical flow rate in a gasoil system:

$Q_{o c}=0.246 \times 10^{-4}\left[\frac{\rho_{o}-\rho_{g}}{\ln \left(r_{e} / r_{w}\right)}\right]\left(\frac{k_{o}}{\mu_{o} B_{o}}\right)\left[h^{2}-\left(h-D_{t}\right)^{2}\right]$

The oil critical rate required to obtain a stable water cone was correlated using the following information: Difference in the oil and water density $\left(\rho_{\mathrm{w}}-\rho_{\mathrm{o}}\right)$; Depth $\mathrm{D}_{\mathrm{b}}$ from the original water-oil contact to the perforations and the height of oil column ish
The intended equation has the following form:

$$
\left.Q_{o c}=0.246 \times 10^{-4}\left[\frac{\rho_{w}-\rho_{o}}{\ln \left(r_{e} / r_{w}\right)}\right]\left(\frac{k_{o}}{\mu_{o} B_{o}}\right)\left[h^{2}-{h_{p}}^{2}\right)\right]
$$

If the effective oil-pay thickness $h$ is made between a gas cap and a water zone, the completion interval must be the type that will allow maximum oil-production rate without having gas and water produced by coning. This case is peculiar in the production from a thin column underlain by bottom water and overlain by a gas cap. For this combined gas and water coning, (Pirson, 1977) combined both the Meyer and Gardner gas-oil and water-oil correlations, Equations 2 and 3 to give the following simplified expression for determining the maximum oil flow rate without gas and water coning in the gas cap and bottom water double threat system:

$$
Q_{o c}=0.246 \times 10^{-4}\left[\frac{h^{2}-h_{p}^{2}}{\ln \left(\frac{r_{e}}{r_{w}}\right)}\right]\left(\frac{k_{o}}{\mu_{o} B_{o}}\right)\left[\left(\rho_{w}-\rho_{o}\right)\left(\frac{\rho_{o}-\rho_{g}}{\rho_{w}-\rho_{g}}\right)^{2}+\left(\rho_{o}-\rho_{g}\right)\left(1-\frac{\rho_{o}-\rho_{g}}{\rho_{w}-\rho_{g}}\right)^{2}\right]
$$

Table1 below is a well and reservoir data for a vertical well

Table 1: Well and reservoir data for a vertical well

\begin{tabular}{|l|l|}
\hline Reservoir Data & Value \& Unit \\
\hline Horizontal, $\mathrm{k}_{\mathrm{h}}$ & $110 \mathrm{md}$ \\
\hline Vertical permeability, $\mathrm{k}_{\mathrm{v}}$ & $110 \mathrm{md}$ \\
\hline Oil relative permeability, $\mathrm{k}_{\mathrm{ro}}$ & 0.85 \\
\hline Oil effective permeability, $\mathrm{k}_{\mathrm{o}}$ & $93.5 \mathrm{md}$ \\
\hline Oil density, $\rho_{\mathrm{o}}$ & $47.5 \mathrm{Ib} / \mathrm{ft}^{3}$ \\
\hline Water density, $\rho_{\mathrm{w}}$ & $63.76 \mathrm{Ib} / \mathrm{ft}^{3}$ \\
\hline Gas density, $\rho_{\mathrm{g}}$ & $5.1 \mathrm{Ib} / \mathrm{ft}^{3}$ \\
\hline Oil viscosity, $\mu_{\mathrm{o}}$ & $0.73 \mathrm{cp}$ \\
\hline Oil formation volume factor, $\mathrm{B}_{\mathrm{o}}$ & $1.1 \mathrm{bbl} / \mathrm{STB}$ \\
\hline Oil column thickness, $\mathrm{h}$ & $65 \mathrm{ft}$. \\
\hline Well Perforated interval, $\mathrm{h}_{\mathrm{p}}$ & $15 \mathrm{ft}$. \\
\hline Depth from GOC to top of perforations, $\mathrm{D}_{\mathrm{t}}$ & $25 \mathrm{ft}$. \\
\hline Wellbore radius, $\mathrm{r}_{\mathrm{w}}$ & $0.25 \mathrm{ft}$. \\
\hline Drainage radius, $\mathrm{r}_{\mathrm{e}}$ & $660 \mathrm{ft}$. \\
\hline
\end{tabular}

The maximum allowable oil rate using data inTable1 to avoid coning breakthrough, i.e., water and gas coning was done manually. Equation 4 was applied to solve for the gas and water coning problem. Pirson (1977) derived an equation for determining the optimum placement of the desired depth of perforation in an oil zone with a gas cap above and a water zone below. Pirson formulated expression to determine optimum distance $\mathrm{D}_{\mathrm{t}}$ from the Gas-Oil-Contact to the top of the perforations can be determined from the following expression:

$D_{t}=\left(h-h_{p}\right)\left[1-\left(\frac{\rho_{o}-\rho_{g}}{\rho_{w}-\rho_{g}}\right)\right]$

*where the distance $\mathrm{D}_{\mathrm{t}}$ is expressed in feet. Using the data given in Table 1, for a vertical well drilled in an oil reservoir overlaid by a gas cap and underlain by bottom water, the optimum distance for the placement of 15-foot perforations was computed by applying Equation 5 .

\section{RESULTS AND DISCUSSION}

Results of Manual computation and prediction using visual basic program for the critical rate and optimum perforation depth placement for the three systems are shown in Table 2.

\begin{tabular}{|c|c|c|}
\hline Coning systems & $\begin{array}{l}\text { Manual Calculation } \\
\text { Results }\end{array}$ & $\begin{array}{lr}\text { Visual } & \text { Basic } \\
\text { Program } & \text { Results }\end{array}$ \\
\hline Gas Coning & $21.20 \mathrm{STB} /$ day & $21.20 \mathrm{STB} /$ day \\
\hline Water Coning & $8.13 \mathrm{STB} /$ day & $8.13 \mathrm{STB} /$ day \\
\hline Combined Gas \& Water Coning & 17.10 STB/day & 17.10 STB/day \\
\hline Optimum Perforation Depth Placement & $13.90 \mathrm{ft}$. & $13.90 \mathrm{ft}$. \\
\hline
\end{tabular}

Table 2: Manual and Program Results.

From Table 2 the manual computation and prediction using Visual basic program are the same. This shows that the program developed was reliable also faster. Effect of perforated Interval, pay-zone thickness and 
fluid properties on critical oil rate were considered and the results are presented below. The program runs in less than 20 seconds, and is a useful aid to field engineers for predicting critical rate and optimum perforation interval depth.

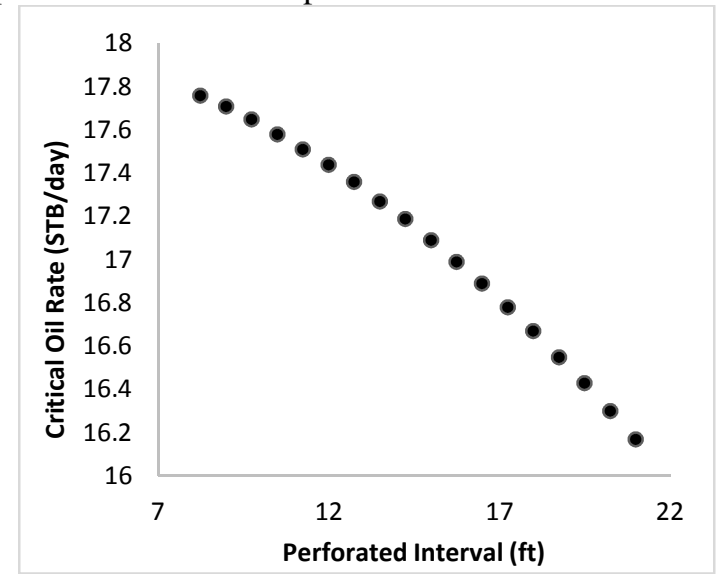

Fig 1 Graph of Critical Oil Rate against Perforated Interval

Figure 1shows effect of perforated interval on critical oil rate was looked at and it was observed that Coning increases as the penetration interval decreases and as the critical oil rate reduces with increasing perforated interval. There two methods that is used to reduce coning. The first method is partial perforation. In this case, only a limited portion of the pay thickness is perforated. The second method is based on the fact that there is a critical producing rate below which the cone stabilizes and will not reach the perforations. Effect of the pay-zone thickness on the critical oil rate was also considered and it was observed that oil critical rate increases as the oil column thickness increases .This tell us that the critical oil rate improves with increasing pay zone thickness. It also suggests that controlling coning in a thin reservoir may be difficult. Effect of oil viscosity was considered and from the result, coning increases as the oil viscosity decreases as the critical oil rate reduces with increasing oil viscosity. Viscous oil is less mobile, which aggravates associated fluids coning.

Figure 2 shows that coning increases as the oil density decreases as the critical oil rate reduces with increasing oil density. Heavy denser oil is more difficult to flow than lighter oil. The density difference between the crude oil and associated fluids plays a role in critical rate determination. Figure 4 illustrate effect of gas density on critical oil rate. The critical oil rate reduces with increasing gas density. From the overall sensitivity analysis of various well and fluid parameters effect on critical oil rate; it can be seen that the perforated interval plays the most vital role in influencing the critical production rate. The oil column thickness, oil viscosity and density, water density and gas density are all factors that cannot be determined, influenced or controlled by the petroleum engineer.

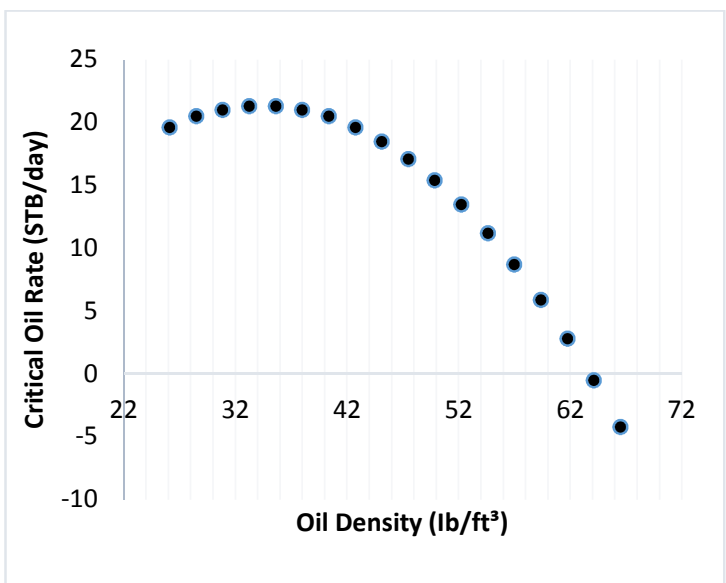

Fig 2 Graph of Critical Oil Rate against Oil Density

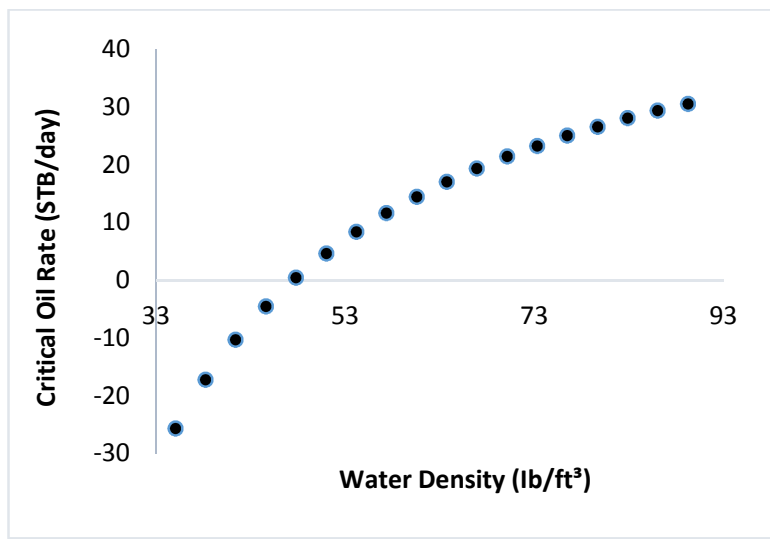

Fig 3: Graph of Critical Oil Rate against Water Density

Figure 3 shows the effect of water density on critical oil rate. Water density increases as the critical oil rate improves with increasing water density.

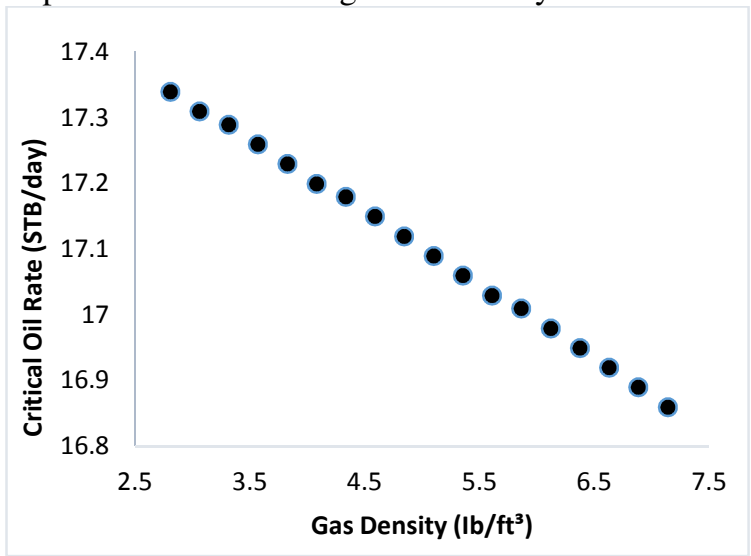

Fig 4 Graph of Critical Oil Rate against Gas Density

The perforated interval however, consequent on effective analysis and computation is to be determined by the engineer, hence the concept of "Optimum 
Perforated Interval Placement' already discussed above as given by Pirson, 1977.

In an oil-bearing zone, which lies below a gassaturated zone, and where water coning is not anticipated, it is best to produce from the bottom of the oil zone. In an actual reservoir, gas will be produced due to its coming out of solution and to the expansion of the gas cap. Therefore, producing from the bottom of the oil zone cannot be expected to eliminate gas production, but only to keep it at a minimum with ordinary completion methods. In oil-bearing sand, which lies above a water-saturated zone, maximum production will be obtained without water breakthrough by producing from the top of the oilsaturated zone.

In a three-phase reservoir, the well should be completed at a depth $\mathrm{D}_{\mathrm{t}}$, given by Equation 1. Meyer and Gardner suggested a method of controlling water coning, the introduction into the formation of an impermeable barrier, extending radially from the bottom of the well. Such a barrier might be made by squeeze cementing techniques in reservoirs where the radial permeability is high compared to the vertical; also, it may be possible to locate the completion of the well above a naturally occurring shale break; or, conceivably, the development of new tools to place an artificial barrier might well be justified. A visual computer program capable of making the necessary computations was developed. The program description, including equations presented in this study, are sufficient for the program to be rewritten. The program runs in less than 20 seconds, and is a useful aid to field engineers for predicting critical rate and optimum perforation interval depth.

Conclusion: Simple visual program has been developed to predict the critical oil production rate for a vertical well in an oil reservoir overlain by gas and/or underlain by water. With this program, field engineers can conveniently predict critical rate and optimum perforation interval placement. Compared to complicated numerical models which are tedious and time consuming.

\section{REFERENCES}

Wheatley, MJ(1985).An Approximate Theory of Oil/Water Coning, SPE 14210, Proceedings of SPE ATCE, Las Vegas, NV September 22-25.

Anietie, NO; Dulu, A; Julius, UA (2017).Water
Coning Prediction Review and Control, Developing an Integrated Approach, .JSRR, 1-24, 2017; Article no.JSRR.33291ISSN: 2320-0227,2.

Ahmed, T (2000). Reservoir Engineering Handbook. 3rd Edition, Elsevier Press, Burlington, MA.

Armenta, M (2003). Mechanisms and Control of Water Inflow to Wells in Gas Reservoirs with Bottom-Water Drive, Ph.D.

Hubbert,MK(1956).Darcy Law and the Field Equations of the Flow of Underground Fluids, Trans.Amer.Inst.Min.Metal.Eng.207, 222-239.

Chaperon, I (1986).Theoretical Study of Coning toward Horizontal and Vertical Wells in Anisotropic Formationsll: Subcritical and Critical Rates. SPE 15377, Proceedings of the SPE 61st ATCE, New Orleans, LA.

Papatzacos, P; Herring, TU; Martinsen, R; Skjaeveland, SM (1991).Cone Breakthrough Time for Horizontal Well, SPE Reservoir Engineering, $311-318$

Yang,W; Wattenbarger, RA (1991).Water Coning Calculations for Vertical and Horizontal Wells, S PE 22931,Proceedings of the SPE $66^{\text {th }}$ ATCE,Dallas,TX,oct.6-9.

Giger, FM (1989). Analytic Two Dimensional Models of Water Cresting before Breakthrough for Horizontal Wells, SPE Reservoir Engineer. J. 409- 416.

Ike, IA (2011). Development of Generalized Well Semi-Analytical Coning Models.

Kwame, S; Afari, S; Aggrey, W (2014). Intelligent Well Technology - Dealing with Gas Coning Problems in Production Wells, Inter. J. Appl. Sci. Technol. 4 (5) 2- 14.

Pirson, SJ (1977).Oil Reservoir Engineering, Robert. E. Krieger Publishing Company, Huntington, NY.

Ike, IA; Debasmite, M (2013). Development of semianalytical post-break through prediction for vertical and horizontal wells. Society of Petroleum Engineers, SPE Paper 167520; 2013. 